\title{
Flight Demonstration Of Low Overpressure N-Wave Sonic Booms And Evanescent Waves
}

\author{
Edward A. Haering, Jr.*, James W. Smolka†, James E. Murray*, \\ and Kenneth J. Plotkin \\ * Research Aerodynamics, NASA Dryden Flight Research Center, Edwards, CA 93523, USA \\ ${ }^{\dagger}$ Research Test Pilot, NASA Dryden Flight Research Center, Edwards, CA 93523, USA \\ "Chief Scientist, Wyle Laboratories, Inc., Arlington, VA 22202, USA
}

\begin{abstract}
The recent flight demonstration of shaped sonic booms shows the potential for quiet overland supersonic flight, which could revolutionize air transport. To successfully design quiet supersonic aircraft, the upper limit of an acceptable noise level must be determined through quantitative recording and subjective human response measurements. Past efforts have concentrated on the use of sonic boom simulators to assess human response, but simulators often cannot reproduce a realistic sonic boom sound. Until now, molecular relaxation effects on low overpressure rise time had never been compared with flight data. Supersonic flight slower than the cutoff Mach number, which generates evanescent waves, also prevents loud sonic booms from impacting the ground. The loudness of these evanescent waves can be computed, but flight measurement validation is needed. A novel flight demonstration technique that generates low overpressure $\mathrm{N}$-waves using conventional military aircraft is outlined, in addition to initial quantitative flight data. As part of this demonstration, evanescent waves also will be recorded.
\end{abstract}

Keywords: Sonic Boom, Flight Data, Evanescent Wave

PACS: 43.25.Cb, 43.28.Gq, 43.28.Mw, 43.50.Lj, 43.50.Rq, 43.50.Yw

\section{HYPOTHESIS}

The inspiration for producing low overpressure $\mathrm{N}$-wave sonic booms originated with the recent measurement of a sonic boom generated by a sounding rocket upon descent[1]. This vehicle was in a very steep dive at a high altitude and low Mach number when it generated the sonic boom that hit the recorder. Sonic booms of this type were desired for recording and analysis, so the sonic boom propagation code PCBoom4[2] was used to look at similar trajectories. Because additional flights of this sounding rocket would be infrequent or nonexistent, alternative available aircraft trajectories were modeled with a multitude of PCBoom4 runs. An aircraft in a steep dive at a high supersonic Mach number was found to generate low overpressures far forward of the dive point. It is hypothesized that these low amplitude booms could be used for human acceptability studies leading to a supersonic aircraft quiet enough for overland flight.

Four attributes have been determined to contribute to low overpressure $\mathrm{N}$-waves generated by conventional aircraft. The first attribute is a very long propagation distance. High vehicle altitude increases propagation distance. The maximum propagation distance occurs when the ray-path extends to near the lateral cutoff. 
The second attribute is the use of shock waves coming from the top of the vehicle. Near-field shock wave probing above and below a B-58 aircraft[3] shows that the shock waves coming from the top of the vehicle are less than those coming from the bottom because of the lift distribution around the aircraft. For the upper surface shock waves to reach the ground (as the primary sonic boom, excluding "over-the-top" booms), the vehicle must be in a dive. An additional benefit of the dive is that less lift is generated on the aircraft, causing less intense shock waves caused by lift.

The third attribute of low overpressure $\mathrm{N}$-waves is the use of the smallest vehicle possible. Although an F/A-18B aircraft was used in this effort, an F-16 aircraft would produce a smaller boom, because it has less boom due to volume. A T-38 aircraft also was considered, but it has the disadvantages of less avionics to aid the pilot in the maneuver and engines that are less forgiving in the high altitude supersonic flight regime. The F/A-18B aircraft was selected, because it was readily available at the NASA Dryden Flight Research Center (Edwards, California), and it had been equipped with the appropriate instrumentation.

The fourth and last attribute is the minimization of Mach number. When a particular Mach number and dive angle was found to produce the desired boom levels on the ground, both Mach number and dive angle could be reduced while maintaining a constant shock wave direction, thus preserving the long propagation path. A lower supersonic Mach number and dive angle also created a condition in which the maneuver was easier to achieve, and more importantly, easier to recover from.

A way to prevent the sonic boom from reaching the ground is to fly slower than the Mach cutoff condition (in the range of Mach 1.1 to 1.3) such that the shock wave refracts up away from the ground. On the ground, only an evanescent wave may be heard, and if heard, would sound much like distant thunder. Flight research on evanescent waves was conducted more than 30 years ago[4], but no high-fidelity recordings were acquired that can be used in human acceptability studies. When they are acquired, such recordings then can be used to validate computational models[5].

\section{EXPERIMENT SETUP}

A flight research project called the Low Boom/No Boom Experiment has been initiated. Four flight phases are planned for this project, but the overarching objective is to aid in the determination of an acceptable noise level for certifiable overland supersonic vehicles. Table 1 presents the specific objective of each flight phase.

TABLE 1. Low Boom/No Boom Experiment Objectives.

\begin{tabular}{|c|c|c|}
\hline $\begin{array}{l}\text { Flight } \\
\text { Phase }\end{array}$ & $\begin{array}{c}\text { Low Boom } \\
\text { (low overpressure N-waves) }\end{array}$ & $\begin{array}{l}\text { No Boom } \\
\text { (evanescent waves) }\end{array}$ \\
\hline 1 & $\begin{array}{l}\text { Assess feasibility and repeatability of } \\
\text { generating low overpressure } \mathrm{N} \text {-waves } \\
\left(<0.6 \mathrm{lbf} / \mathrm{ft}^{2}\right) \text { in a specified geographic area }\end{array}$ & $\begin{array}{l}\text { Gather limited digital high-fidelity } \\
\text { microphone data for validation of } \\
\text { evanescent wave loudness predictions }\end{array}$ \\
\hline 2 & \multicolumn{2}{|c|}{$\begin{array}{l}\text { Gather high-fidelity, statistically significant data for loudness levels and operational } \\
\text { considerations (atmospheric variability effects) }\end{array}$} \\
\hline 3 & \multicolumn{2}{|c|}{ Perform outdoor human response surveys with flights within the restricted airspace } \\
\hline 4 & \multicolumn{2}{|c|}{$\begin{array}{l}\text { Perform outdoor human response surveys with flights outside the restricted airspace } \\
\text { (populated areas) }\end{array}$} \\
\hline
\end{tabular}


To implement the first phase of this experiment, a NASA Dryden F/A-18B aircraft equipped with several instrumentation packages is employed. A Research Quick Data System (RQDS) acts as the 1553 bus monitor of the aircraft parameters, including airdata and inertial navigation system parameters, which are telemetered to the ground for recording and real-time sonic boom footprint calculations. A time code generator with an embedded global positioning system (GPS) receiver is used to time-stamp the RQDS data.

In the transonic flight region the F/A-18B aircraft is known to have airdata position errors[6] on the order of $2,000 \mathrm{ft}$ of altitude. Additionally, the steep dives that are performed may induce significant pneumatic lag in the aircraft airdata system. To provide the necessary additional calibration for position error and lag, a carrier-phase differential GPS receiver (that provides accurate inertial position and speeds) was installed in the aircraft. The initiation of the supersonic dive involves rolling the aircraft to an inverted attitude before diving, causing the GPS to lose data. For these maneuvers, ground-based radar tracking was obtained using a C-band radar beacon on the aircraft.

For the airdata calibrations and PCBoom4 sonic boom propagation codes, accurate measurements of the atmospheric conditions are needed. The GPS rawinsonde balloons and wind profiler data are used for atmospheric analysis. Some of these sensors will be deployed at the location of the microphone array.

Microphones were placed over many miles of relatively flat desert terrain under a supersonic corridor. The spacing of the microphones was chosen to obtain a range of overpressures while allowing for atmospheric variability in footprint location. Several NASA Dryden Boom Amplitude and Shape Sensors (BASS) and Boom Amplitude and Direnction Sensors (BADS[7]) were used to record the low booms in phase 1. A few Bruel and Kjær (Denmark) 4193 microphones will be used to record evanescent waves for phase 1 .

Various dive profiles first were practiced in the NASA Dryden F/A-18 flight simulator. The current dive profile involves flying at a level attitude, high subsonic speed, and altitude of nearly 50,000 ft. The aircraft is rolled to an inverted attitude; a positive $g$ pull to the desired dive angle of $53^{\circ}$ downward then is initiated, while the throttle is pulled to the idle position to avoid excessive speed. When the desired dive angle is reached, the aircraft is rolled to an upright attitude, and a Mach number of approximately 1.1 is achieved. At an altitude of $38,000 \mathrm{ft}$ a pull-up is executed to recover the aircraft at an altitude of approximately 32,000 ft. The F/A-18B aircraft has an angle-of-attack limit in this supersonic flight regime, so angle of attack is closely monitored. The F/A-18 avionics allows a dive point to be displayed on the head-up display (HUD), which greatly aids in maintaining the proper dive angle and heading. The PCBoom4 runs of the simulation data predicted overpressures down to approximately $0.2 \mathrm{lbf} / \mathrm{ft}^{2}$.

\section{INITIAL RESULTS}

The supersonic dives were practiced during a checkout flight of the RQDS system on the F/A-18B aircraft. At the same time, the BASS recorders underwent field checkouts while candidate microphone locations were sought. Although the surface 
weather was sometimes quite breezy, low overpressure $\mathrm{N}$-wave sonic booms were recorded on multiple dives. Figure 1 shows two sets of these sonic boom measurements.
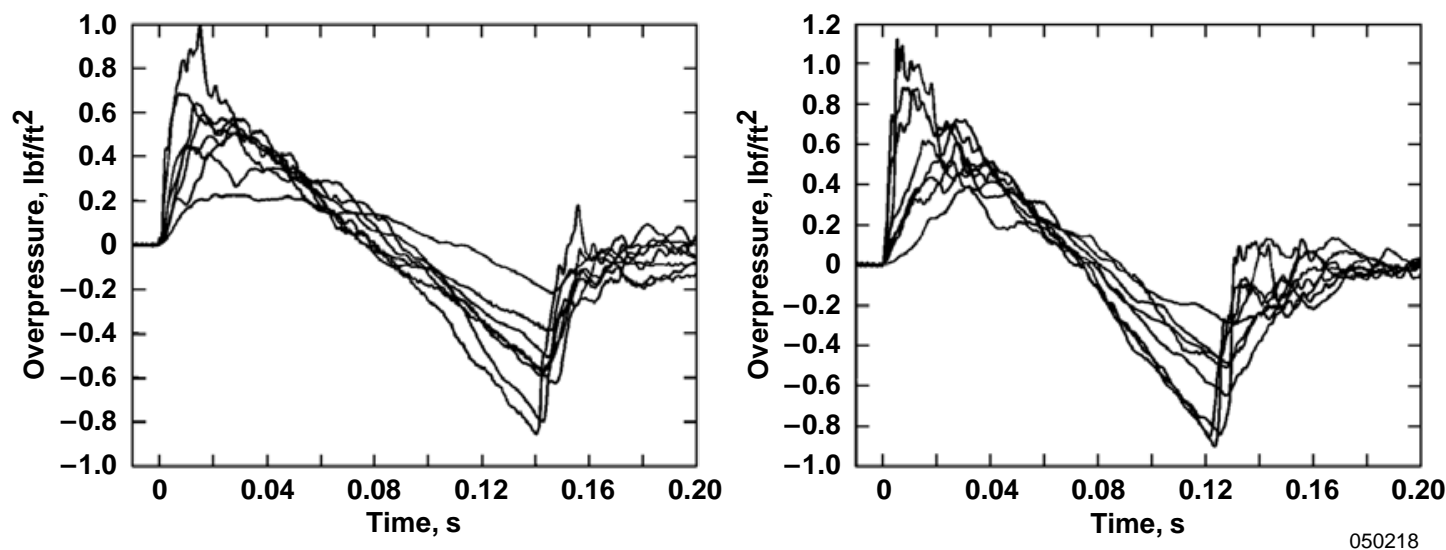

FIGURE 1. Initial ground-level sonic boom measurements from the $\mathrm{F} / \mathrm{A}-18 \mathrm{~B}$ aircraft in a supersonic low boom dive. Dive no. 3 is on the left, and dive no. 5 is on the right (April 1, 2005).

The microphones were spaced apart over 6 miles parallel to the ground track, and an additional microphone was placed 1 mile off of the track. The ground sensor sites located farthest from the aircraft generally show the lowest overpressure, and overpressure increases as the dive location is approached. Atmospheric turbulence is evident with repeated artifacts in each bow and tail shock. The rise time of the signature greatly increases with decreasing maximum overpressure, as much as $40 \mathrm{~ms}$ for one signature. The airdata calibration and lag determination has not yet been completed, and no radar tracking or local weather balloon data were obtained from this flight, but the experiment participants were very pleased to have obtained low overpressure $\mathrm{N}$-waves on the first attempt, even in nonoptimal weather conditions. Such low overpressure sonic booms bracket the probable acceptable noise level and can be used for human subjective testing.

\section{REFERENCES}

1. Plotkin, K. J., Haering, E. A., Jr., and Murray, J. E., "Low-Amplitude Sonic Boom From a Descending Sounding Rocket," Proceedings of the $17^{\text {th }}$ International Symposium on Nonlinear Acoustics, American Institute of Physics, Melville, New York, July 2005.

2. Plotkin, K. J., and Grandi, F., Computer Models for Sonic Boom Analysis: PCBoom4, CABoom, BooMap, CORBoom, Wyle Report WR 02-11, June 2002.

3. Maglieri, D. J., Ritchie, V. S., and Bryant, J. F., Jr., In-Flight Shock-Wave Pressure Measurements Above and Below a Bomber Airplane at Mach Numbers from 1.42 to 1.69, NASA TN D-1968, 1963.

4. Haglund, G. T., and Kane, E. J., Flight Test Measurements and Analysis of Sonic Boom Phenomena Near the Shock Wave Extremity, NASA CR-2167, 1973.

5. Fung, K. Y., "Shock Wave Formation at a Caustic," SIAM Journal of Applied Mathematics, Vol. 39, No. 2, pp. 355-371, Oct. 1980.

6. Haering, E. A., Jr., Airdata Measurement and Calibration, NASA TM-104316, 1995.

7. Plotkin, K. J., Haering, E. A., Jr., Murray, J. E., Maglieri, D. J., Salamone, J., Sullivan, B. M., and Schein, D., "Ground Data Collection of Shaped Sonic Boom Experiment Aircraft Pressure Signatures," AIAA-2005-010, Jan. 2005. 